\title{
Kronik hepatit B hastalarında ortalama trombosit hacmi, nötrofil/lenfosit oranı ile fibrozis arasındaki ilişki
}

\author{
Relationship between neutrophil-to-lymphocyte ratio, mean platelet volume, and fibrosis level in \\ patients with chronic hepatitis $B$
}

\author{
Kadri ATAY \\ Mardin Devlet Hastanesi, Gastroenteroloji Bölümü, Mardin
}

Giriş ve Amaç: Karaciğer biyopsisi kronik hepatit hastalığında karaciğer hasarını göstermek için halen altın standart yöntem olmakla beraber, günümüzde karaciğer hasarını daha kolay belirleyebilmek için birçok noninvaziv test araştırılmıştır. Bu çalışmada amacımız kronik hepatit B hastalarında fibrozis belirteci olarak ortalama trombosit hacmi ve nötrofil lenfosit oranı ilişkisini araştırmaktır. Gereç ve Yöntem: Çalışmaya 44 kronik hepatit B hastası ve 33 sağlıklı kişiden oluşan kontrol grubu alındı. Hasta ve kontrol grupları arasında karşılaştırılmalar yapıldı, ayrıca kronik hepatit $B$ hastaları fibrozis skoruna göre hafif fibrozis ve ileri fibrozis olanlar olmak üzere iki gruba ayrılarak karşılaştırmalar yapıldı. Bulgular: Kronik hepatit $B$ hastalarının yaş ortalaması $43 \pm 16$ ve kontrol grubunun yaş ortalaması $41 \pm 19$ idi. Kronik hepatit $B$ grubunda ortalama trombosit hacmi $10.6 \pm 1.2$ ve kontrol grubunda $9.5 \pm 0.6$ bulundu. Bu iki grup arasında istatistiksel fark olduğu görüldü $(p=0.0001)$. Kronik hepatit $B$ hastaları ve kontrol grubu arasında nötrofil lenfosit oranları arasında anlamlı fark saptanmadı $(p=0.29)$. Fibrozis skoru hafif ve ileri olan hastaların ortalama trombosit hacmi düzeyleri karşılaştırıldığında fibrozis skoru hafif olan hastalarda ortalama trombosit hacmi değerleri-

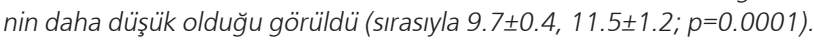
ROC analizinde ortalama trombosit hacminin ileri fibrozisi saptanmastnın en iyi kesim değeri 10,25 alındığında, sensitivitesi \%86, spesifitesi \%99 olarak bulundu (EAA 0.94; 95\% Cl; p<0.0001). Sonuç: Bu çalışma ortalama trombosit hacmi değerinin kronik hepatit $B$ hastalarında artmış olduğunu ve artmış ortalama trombosit hacmi değerlerinin kronik hepatit B hastalarında ileri fibrozisi tahmin etmede yardımcı olabileceğini göstermiştir.

Anahtar kelimeler: Fibrozis, nötrofil lenfosit oranı, ortalama trombosit hacmi

\section{Gíriş}

Hepatit B virüsü (HBV) kronik hepatit, siroz ve hepatosellüler kanserin (HCC) halen en sık nedeni olup günümüzde halen ciddi bir sağlık sorunu olmaya devam etmektedir. Dünya nüfusunun yaklaşık \%5'inin hepatit B yüzey antijeni (HBsAg) taşıyıcısı olduğu bildirilmektedir (1). Kronik HBV taşıyıcılarının sayısı günümüzde yaklaşık 350 milyonu geçmiş olup her yıl yaklaşık bir milyon hasta HBV enfeksiyonunun neden olduğu komplikasyonlardan ölmektedir (2-4). Kronik HBV enfeksiyonu olan hastaların \%20-30

Illetişim: Kadri ATAY

Mardin Devlet HastanesiGastroenteroloji Bölümü, Mardin

E-mail: dr_kadrii@yahoo.com
Background and Aims: Hepatitis B virus infection remains a major health problem worldwide. Although liver biopsy is the gold standard procedure for documenting liver damage in chronic hepatitis, many noninvasive tests have been investigated for the determination of liver damage. The aim of this study was to evaluate the role of mean platelet volume and neutrophil lymphocyte ratio as markers of fibrosis in patients with chronic hepatitis B. Material and Methods: The study included 44 patients with chronic hepatitis $B$ and 33 healthy subjects as the control group. Demographic and laboratory data were recorded. Patients with chronic hepatitis B were compared with the control group. Patients with chronic hepatitis $B$ infection were then divided into two groups, mild fibrosis and advanced fibrosis, and these two groups were compared. Results: The mean age of patients with chronic hepatitis $B$ was $43 \pm 16$ years, and the mean age of the control group was $41 \pm 19$ years. The mean platelet volume was $10.6 \pm 1.2$ in the chronic hepatitis $B$ group and $9.5 \pm 0.6$ in the control group. There was a statistically significant difference between the groups $(p=0.0001)$. mean platelet volume levels of patients with mild fibrosis were significantly lower than those of patients with advanced fibrosis (respectively, $9.7 \pm 0.4,11.5 \pm 1.2 ; p=0.0001$ ). There was no statistically significant difference in the neutrophil-to-lymphocyte ratio between the chronic hepatitis $B$ and control groups. Receiver operating characteristic curves were used to assess advanced fibrosis in mean platelet volume and mean platelet volume. The cut-off value for the prediction of advanced fibrosis was 10.25 , with a sensitivity and specificity of $86 \%$ and $99 \%$, respectively (AUC 0.94; 95\% Cl; $p<0.0001$ ). Conclusion: The present study demonstrated that mean platelet volume is increased in chronic hepatitis $B$, and high mean platelet volume levels may help to predict advanced fibrosis in patients with chronic hepatitis $B$.

Key words: Fibrosis, neutrophil-to-lymphocyte ratio, mean platelet volume

kadarında hastalık ilerleyici olup son dönem karaciğer yetmezliği olan siroza neden olmaktadır (5). Günümüzdeki klinik uygulamalara göre ilerleyici kronik karaciğer hastalığı tanısı ve tedavisi için karaciğer biyopsisi gereklidir. Karaciğerdeki hasarı değerlendirmek için yapılan karaciğer biyopsisi günümüzde halen altın standart olup hastalığın histolojik aktivitesi ve fibrozis evresi hakkında önemli bilgiler vermekte, hastalığın seyri ve tedavi sonuçları hakkında önceden bize bilgi sağlamaktadır. Ancak

ATAY K. Relationship between neutrophil-to-lymphocyte ratio, mean platelet volume, and fibrosis level in patients with chronic hepatitis B. The Turkish Journal of Academic Gastroenterology 2019;18:7-11. DOI: 10.17941/agd.543387

Geliş Tarihi: 07.02.2019 • Kabul Tarihi: 06.03.2019 
karaciğer biyopsisi invaziv, bazen komplike olabilen, maliyetli ve uzman bir patolog görüşü gerektiren zahmetli bir işlemdir $(6,7)$. Karaciğer biyopsisi için hasta çekinceleri de göz önüne alındığında kronik HBV hastalarının mevcut hastalık durumu ve fibrozis değerlendirilmesinde invaziv olmayan histolojik göstergelere ihtiyaç duyulmaktadır. En azından karaciğer biyopsisi yapılamayan hastalar için klinik pratikte kullanılabilecek biyokimyasal tetkiklerin yararlı olabileceği düşünülmektedir ve bu konuda araştırmalar devam etmektedir (8). Trombosit hacmi (MPV) trombosit fonksiyonunu belirlemekte ve artmış trombosit aktivasyonunu yansıtmaktadır (9). Özellikle son zamanlarda ortalama trombosit hacmi ve bazı hastalıkların klinik önemi ile ilgili yapılmış birçok çalışma bulunmaktadır (10-15). Nötrofil/lenfosit oranının, akut veya kronik viral hepatitlerde karaciğer yetersizliği tablosu olduğunda mortalitenin ön görülmesinde ve karaciğer nakli sonrası HCC nüksünün belirlenmesinde yol gösterici olabileceği ifade edilmektedir $(16,17)$. Bu çalışmada, kronik hepatit B hastalarında ortalama trombosit hacmi, nötrofil/lenfosit oranı değerlerini belirlemek ve bu parametrelerin karaciğer fibrozis düzeyi ile ilişkisini araştırmak amaçlanmaktadır.

\section{GEREÇ ve YÖNTEM}

$\mathrm{Bu}$ retrospektif çalışmaya gastroenteroloji polikliniğinde karaciğer biyopsisi yapılıp takip edilen 44 kronik hepatit B hastası (KHB) ve kontrol grubu olarak 33 sağlıklı kişi dahil edildi. Çalışmaya alınan hastalar HBsAg pozitifliği 6 aydan uzun süreli devam eden ve HBV DNA düzeyi $>2000 \mathrm{IU} / \mathrm{ml}$ olup, biyopsi yapılmış olanlardan oluşmaktaydı. Ek yandaş kronik hastalığı olanlar çalışma dışı bırakıldı. Grupların yaş, cinsiyet ve ortalama trombosit hacmi ve nötrofil/lenfosit oran değerlerinin karşılaştıııması yapıldı. Hastaların tedavi öncesi yapılan biyopsileri incelendi. Kronik hepatit
B hastaları fibrozis skoruna göre iki gruba ayrıldı. Gruplar ise Ishak fibrozis skoruna göre hafif fibrozis (skoru 0-3) olanlar ve ileri fibrozis (skoru 4-6) olanlar olarak belirlendi.

\section{İstatistiksel Analiz}

Sayısal veriler ortalama \pm standart sapma, kategorik veriler ise oran olarak ifade edildi. Verilerin normal dağılıp dağılmadığı Kolmogorov-Smirnov testi kullanılarak değerlendirildi. Normal dağılıma uyan verilerin istatistiğinde t-test, normal dağılıma uymayan verilerin karşılaştııımasında ise Mann-Whitney U testi kullanıldı. Kategorik veriler Ki kare testi ile karşılaştıııldı. Normal dağılıma uyan verilerin korelasyonunda Pearson korelasyon testi, normal dağılıma uymayan verilerin korelasyonunda ise Spearman korelasyon testi kullanıldı. Hasta bilgileri SPSS 21.0 programı kullanılarak analiz edildi. İstatistiksel anlamlılık $p<0.05$ olarak kabul edildi.

\section{BULGULAR}

Kronik hepatit B grubunda bulunanların yaş ortalaması $43 \pm 16$ ve kontrol grubunda bulunanların ise yaş $41 \pm 19$ olarak saptandı. Hasta grubunda erkek oranı \%50, kontrol grubunda \%51.5 idi ve her iki grup arasında yaş ortalaması ve cinsiyet yönünden anlamlı fark yoktu $(p>0.05)$. KHB grubunda MPV 10.66 \pm 1.29 , kontrol grubunda $9.59 \pm 0.69$ idi ve istatistiksel olarak anlamlı fark olduğu saptandı ( $p=0.001$ ). Bulgular Tablo 1'de görülmektedir.

Hasta ve kontrol grupları, nötrofil sayısı, lenfosit sayısı ve nötrofil lenfosit oranı yönünden karşılaştıııldığında gruplar arasında anlamlı fark saptanmadı (sırasıyla $p=0.8$, $p=0.15, p=0.29$ ). Gruplar arasında trombosit değerleri ve hemoglobin değerleri arasında istatistiksel olarak anlamlı fark saptandı (sırasıyla $p=0.001, p=0.02$ ) (Tablo 1).

Tablo 1. Kronik hepatit B ve kontrol grubunun demografik bulguları ve laboratuvar değerleri

\begin{tabular}{|lccc} 
& Kronik Hepatit B Grubu (44) & Kontrol Grubu (33) & p \\
\hline Yaş (ortalama \pm SD) (yıl) & $43 \pm 16$ & $41 \pm 19$ & 0.2 \\
\hline Cinsiyet (K/E) & $22 / 22$ & $16 / 17$ & 0.8 \\
\hline MPV (fL) & $10.6 \pm 1.2$ & $9.5 \pm 0.6$ & 0.0001 \\
\hline Nötrofil/Lenf oranı & $2.1 \pm 0.7$ & $1.9 \pm 0.4$ & 0.29 \\
\hline Nötrofil & $4280 \pm 1313$ & $4330 \pm 1003$ & 0.85 \\
\hline Lenfosit & $2129 \pm 590$ & $2325 \pm 673$ & 0.18 \\
\hline Hemoglobin $(\mathrm{g} / \mathrm{dl})$ & $14.8 \pm 1.5$ & $13.8 \pm 1.8$ & 0.02 \\
\hline Trombosit $\left(150-450 \times 10^{3} / \mu \mathrm{L}\right)$ & $273 \pm 65$ & 0.001 \\
\hline MCV & $206 \pm 93$ & $84.2 \pm 6.7$ & 0.2 \\
\hline
\end{tabular}

MPV: Ortalama trombosit hacmi, MCV: Ortalama hücre volümü. 
Tablo 2. İleri fibrozis ve hafif fibrozis hastalarının demografik bulguları ve laboratuvar değerleri

\begin{tabular}{lccc} 
& Hafif Fibrozis Grubu (22) & ileri Fibrozis Grubu (22) & p \\
\hline Yaş (ortalama \pm SD) (yll) & $34 \pm 12$ & $52 \pm 13$ & 0.001 \\
\hline Cinsiyet (K/E) & $7 / 15$ & $15 / 7$ & 0.017 \\
\hline MPV (fL) & $9.7 \pm 0.4$ & $11.5 \pm 1.2$ & 0.0001 \\
\hline Nötrofil/Lenf oranı & $1.9 \pm 0.65$ & $2.1 \pm 0.85$ & 0.5
\end{tabular}

Fibrozis skoruna göre iki gruba ayırdığımız KHB hastalarının karşılaştırılmasına bakıldığında fibrozis düzeyi ileri olan grupta yaş ortalamasının daha büyük olduğu ve bunun istatistiksel olarak anlamlı olduğu görülürken (sırasıyla $52 \pm 13,34 \pm 12, p=0.001$ ) yine cinsiyet açısından bakıldığında fibrozis düzeyi ileri olan grupta kadın sıklığının daha fazla olduğu ve istatiksel olarak anlamlılığa rastlanmıştır $(p=0.001)$. Yine fibrozis skoru düşük ve yüksek grupların arasındaki MPV değerlerine bakıldığında ise fibrozis düzeyi ileri olanlarda MPV değerinin daha yüksek olduğu ve istatistiksel olarak anlamlı olduğu görülmüştür (sırasıyla ileri fibrozis grubu 11.56 \pm 1.23 , düşük fibrozis grubu $9.76 \pm 0.45 p=0.001)$. Benzer şekilde fibrozis skoruna göre hafif ve ileri fibrozis diye iki gruba ayırdığımız KHB hastalarının karşılaştııımasına bakıldığında ise nötrofil lenfosit oranı değerleri yönünden anlamlı fark olmadığı saptanmıştır $(p=0.5)$ (Tablo 2).

Korelasyon analizinde hasta ve kontrol gruplarında trombosit sayısı ile MPV arasında negatif korelasyon saptanırken (sırasıyla $r=-0.44, p=0.01$ ), trombosit sayısı ile nötrofil sayısı arasında negatif korelasyon saptandı $(r=-0.46$, $p=0.01$ ). Hasta grubunda nötrofil lenfosit oranı ile fibrozis arasında korelasyon saptanmadı $(r=0.41, p=0.3)$. Hasta grubunda MPV ile fibrozis arasında pozitif ve anlamlı korelasyon saptandı $(r=0.41, p=0.03)$. Yine MPV ile hepatik aktivite arasında pozitif korelasyon mevcuttu $(r=0.40$, $\mathrm{p}=0.01$ ).

ROC curve analizi sonucunda MPV'nin ileri fibrozisi saptamasının en iyi kesim değeri 10,25 olarak bulundu $(p=0.001)$ (Şekil 1). İleri fibrozisi saptama açısından MPV sonuçları değerlendirildiğinde; kesim değeri $\geq 10,25$ olarak alındığında sensitivite $\% 86$, spesifite $\% 99$, pozitif prediktif değer \%95 ve negatif prediktif değer \%87 olarak bulundu.

\section{TARTISSMA}

Çalışmamızda hepatit B tedavisi almamış ve karaciğer biyopsisi yeni yapılmış 44 kronik hepatit B'li hasta ile 33 sağ|ıkı kontrolün MPV, nötrofil lenfosit oranlarının karşılaştırmalarını ve bu değerlerin karaciğerdeki fibrozis ile

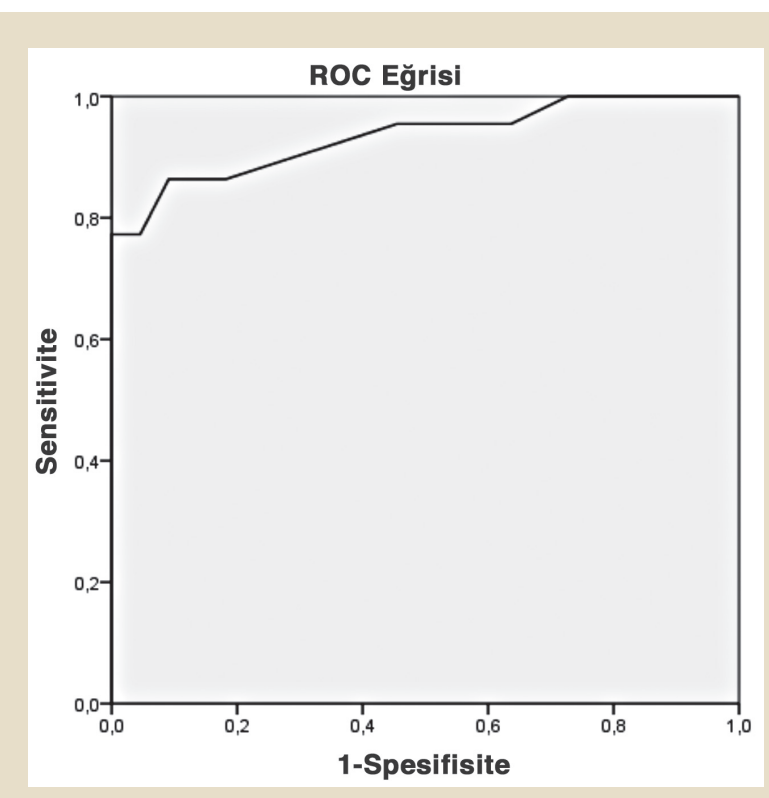

Şekil 1. MPV değeri için ROC eğrisi, eğri altında kalan alan $=0.94, p=0.001$

olan korelasyonunu inceledik. HBV hastaları ile kontrol grubu arasında MPV değerleri arasında istatistiksel olarak anlamlı farklılık saptadık. MPV ile fibrozis arasında anlamlı korelasyon saptanırken, nötrofil lenfosit oranı ile fibrozis arasında anlamlı korelasyon saptayamadık. ROC eğrisinde ise ileri fibrozisi saptamada MPV değeri 10,25 alındığında sensitiviteyi $\% 85$ ve spesifiteyi $\% 99$ ve pozitif prediktif değeri \%95 ve negatif prediktif değeri \%87 olarak saptadık.

Hepatit B enfeksiyonu tüm dünyada halen yaygın bir problem olarak görülmekte ve ilerleyen dönemlerde siroz, hepatosellüler kanser gibi komplikasyonlara neden olabilmektedir (18). Ülkemizde kronik hepatit enfeksiyonu olan hastalara antiviral tedavi başlanmadan önce invaziv bir yöntem olan karaciğer biyopsisi yaptırma şartı mevcuttur. Karaciğer biyopsisi özellikle kanama gibi çeşitli komplikasyonlara yol açabildiğinden dolayı özellikle son dönemlerde karaciğerdeki fibrozisi saptamada hastada komplikasyon riski olmayan noninvaziv testlerin etkinlikleri araştırılmaktadır (19). 
Trombositler hemostazda primer bir rol oynamaktadır. Kronik karaciğer hastalıklarında trombosit parametrelerinde değişikliklerin meydana geldiği bilinmektedir (20). MPV'deki artış ile trombositlerde aktivasyonun arttığı, salgıladıkları bazı sitokin ve diğer mediatörlerle daha kolay agregasyon yaptıkları ve çeşitli hastalıklara neden olabileceği bildirilmiştir (21). Ortalama trombosit hacminin çeşitli hastalıkların klinik yararına kullanımıyla ile ilgili ülkemizden de konuyla ilgili yapılmış çalışmalar bulunmaktadır $(15,23,24)$. Hepatit hastaları ve MPV ile ilgili Ekiz ve ark. yapmış oldukları çalışmada KHB hastalarında MPV değerini 8.49 \pm 0.84 , kontrol grubunda 7.65 \pm 0.42 olarak saptamış olup hasta ve kontrol grupları arasında istatistiksel olarak anlamlı fark olduğunu bildirmişlerdir (25). Turhan ve ark.nın 260 inaktif hepatit B taşıyıcısı ile yapmış oldukları çalışmada MPV inaktif taşıyıcılarda

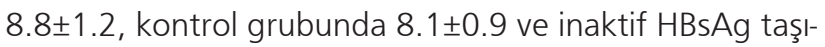
yıcı grubunda anlamlı derecede yüksek saptanmıştır (26). Hepatit C hastaları ile yapılmış çalışmalara bakıldığında ise MPV'nin kronik hepatit $C$ hasta gruplarında (sırasıyla

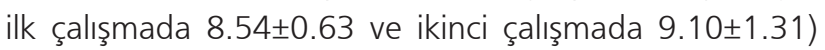
kontrol gruplarına göre anlamlı oranda yüksek olduğu bulunmuştur ( $p$ : <0.001) $(27,28)$. Kendi yapmış olduğumuz çalışmamızda kronik hepatit B hastalarında MPV değerlerini hasta grubunda 10.66 \pm 1.29 , kontrol grubunda $9.59 \pm 0.69$ olarak bulmuş olup, istatiksel olarak anlamlılık saptadık $(p=0.001)$.

Aygün ve arkadaşları bu konuyla ilgili yapmış oldukları çalışmada, yüksek fibrozisi olan grupta yaşın daha ileri olduğunu ve bunun istatistiksel olarak anlamlı olduğunu bildirmişlerdir (8). Ekiz ve arkadaşlarının KHB hastaları ile yapılmış olan çalışmasında ileri fibrozisi olan hastalarda MPV'nin daha yüksek olduğu ve istatistiksel olarak anlam-

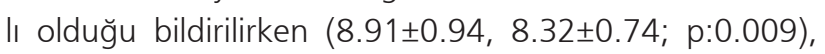
hepatit $C$ hastaları ile yapılmış çalışmada ise ileri fibrozisi olan hastalarda MPV'nin yüksek olduğu bildirilmiştir (sırasılla 8.99 $\pm 0.57,8.19 \pm 0.50 ; p<0.001)(26,27)$. Ceylan ve arkadaşları, kronik hepatit B hastalarını fibrozis skoruna göre iki gruba (grup 1: fibrozis skoru 0-3 olanlar, grup 2: fibrozis skoru 4-6 olanlar) ayırarak yapmış oldukları çaIsşmada MPV'yi grup 1'de 8.7, grup 2'de 9.4 saptamışlar, MPV'nin değerinin diğer belirteçlerle birlikte yapılan formül ile karaciğer iltihabı derecesini tahmin etmek için yararlı bilgiler sağlayabileceğini bildirmişlerdir (29). Yine bir diğer çalışmada MPV'nin karaciğer fibrozis şiddetinin

\section{KAYNAKLAR}

1. Cengiz T, Kıyan M, Yavaşoğlu O, et al. HBsAg taşıyıcılarının yakın aile çevresindeki bireylerde ELISA ile HBsAg'ın araştırılması. OMÜ Tıp Dergisi 1992;9:137-43. belirlenmesinde kullanılabileceği belirtilmiştir (30). Yukarıda bahsedilen literatürdeki çalışmalara benzer şekilde biz de çalışmamızda KHB hastalarını fibrozis skoruna göre iki gruba ayırıp yaptığımız karşılaştırmada ileri fibrozisi olanlarda yaşın daha büyük olduğunu ve kadın hasta sayısının ileri fibrozisli hastalarda daha baskın olduğunu ve bunların istatistiksel olarak anlamlı olduklarını saptadık.

Nötrofil lenfosit oranı (NLO), gündelik hayatımızda rutin olarak çalışılan tam kan sayımından elde edilebilen ucuz ve kolay ulaşılabilen bir belirteçlerdir. NLO, akut veya kronik viral hepatitlerde karaciğer yetersizliği gelişen olgularda mortalitenin ön görülmesinde ve karaciğer nakli sonrası HCC nüksünün belirlenmesinde yol gösterici olabilecek bir parametre olarak ifade edilmektedir $(17,30)$. İnaktif HBV taşıyıcılarında, yüksek dereceli karaciğer fibrozis hastalarında NLO'nun daha düşük olduğu ifade edilmiştir (31). Yeşil ve ark. hepatit B'li hastaların nötrofil/ lenfosit oranı ve fibrozis arasındaki ilişki ile ilgili yapmış oldukları çalışmada fibrozis skoru ile nötrofil/lenfosit ora$\mathrm{nı}(\mathrm{r}:+0,510, \mathrm{p}: 0,0001)$ arasında anlamlı korelasyon saptamışlardır (32). Uluca ve arkadaşları hepatit B'lilerde yapmış oldukları benzer çalışmada nötrofil/lenfosit oranı ile fibrozis arasında anlamlı bir ilişki saptayamamışlardır (33). Benzer şekilde Chen ve ark. tarafından yapılan çalışmada da kronik hepatit B grubu ile kontrol grubu arasında fark saptanmamıştır (34). Biz kendi çalışmamızda ise Uluca ve Chen ark.'nin yapmış oldukları çalışmalara benzer şekilde nötrofil/lenfosit oranı ile fibrozis arasında anlamlı bir ilişki saptayamadık.

Çalışmamızın temel kısıtlılıkları, hasta ve kontrol grupları popülasyonlarının az olmasıydı. Sonuç olarak kronik HBV takip ve tedavisinde altın standartın karaciğer biyopsisi olduğu bilinmektedir. Ancak her zaman biyopsi yapmak mümkün olmamakta ve karaciğer histopatalojisini öngörebilmek için bazı belirteçler kullanılmasına intiyaç duyulmaktadır. Çalışmamızda nötrofil/lenfosit oranı ile fibrozis arasında anlamlı bir ilişki saptayamamıza rağmen MPV'nin KHB hastalarında kontrol grubundan daha yüksek ve fibrozis düzeyi ileri olan hasta grubunda daha yüksek olduğu belirlenmiştir. Çalışmamız KHB hastalarına MPV değerlerinin karaciğer fibrozisi hakkında ek bilgi sağlayabileceğini düşündürmektedir. Kronik hepatit $B$ hastalarında MPV değişiklikleri ile ilgili daha geniş serili ve daha fazla sayıda hasta ile yapılan çalışmalara ihtiyaç duyulduğunu düşünmekteyiz. 
3. Mahoney FJ. Update on diagnosis, management and prevention of hepatitis B virüs infection. Clin Microbiol Rev 1999;12:351-66.

4. Lee WM. Hepatitis B infection. N Eng J Med 1997;337:1733-45.

5. Fattovich G, Brollo L, Giustina G, et al. Natural history and prognostic factors for chronic hepatitis type B. Gut 1991;32:294-8.

6. McGill DB, Rakela J, Zinsmeister AR, Ott BJ. A 21-year experience with majör hemorrhage after percutaneous liver biopsy. Gastroenterology 1990;99:1396-400.

7. Regev A, Berho M, Jeffers LJ, et al. Sampling error and intraobserver variation in liver biopsy in patients with chronic HCV infection. Am J Gastroenterol 2002;97:2614-8.

8. Aygün C, Gözel N, Demiral U, et al. Kronik viral hepatit B tanısı olan hastalarda serum GGT düzeyi ile karaciğer fibrozu ilişkisi. Fırat Tıp Dergisi 2010;15:74-8.

9. Hendra TJ, Oswald GA, Yudkin JS. Increased mean platelet volume after acute myocardial infarction relates to diabetes and to cardiac failure. Diabetes Res Clin Pract 1988;5:63-9.

10. Topal F, Topal FE, Akbulut $\mathrm{S}$. Ailesel Akdeniz ateşi ve irritabl barsak sendromunun ayırıcı tanısında ortalama platelet hacminin rolü. Sakarya Medical Journal 2012;2:186-9.

11. Keskin S, Gürler M, Temeloğlu E, et al. Ortalama trombosit hacminin koroner arter hastalığı risk faktörleriyle ilişkisi. Türkiye Klinikleri J Med Sci 2006;26:380-4.

12. Yüksel $\mathrm{O}$, Helvaci $\mathrm{K}$, Başar $\mathrm{O}$, et al. An over looked indicator of disease activity in ulcerative colitis: mean platelet volume. Platelets 2009;20:277-81.

13. Kisacik B, Tufan A, Kalyoncu U, et al. Mean platelet volume (MPV) as an inflammatory marker in ankylosing spondylitis and rheumatoid arthritis. Joint Bone Spine 2008;75:291-4.

14. Tozkoparan E, Deniz O, Ucar E, et al. Changes in platelet count and indices in pulmonary tuberculosis. Clin Chem Lab Med 2007:45:1009-13

15. Alagözlü $H$, Sezer N, Yıldırım B. Myokard infarktüs ve iskemik inmeli hastalarda ortalama trombosit hacmi. CU Tıp Fakültesi Dergisi 2000;22:149-52.

16. Liu H, Zhang H, Wan G, et al. Neutrophil-lymphocyte ratio: a novel predictor for short-term prognosis in acute-on-chronic hepatitis $B$ liver failure. J Viral Hepat 2014;21:499-507.

17. Xiao GQ, Liu C, Liu DL, et al. Neutrophil lymphocyte ratio predicts the prognosis of patients with hepatocellular carcinoma after liver transplantation. World J Gastroenterol 2013;19:8398-407.

18. Biçeroğlu SU, Yazan Sertöz R, Zeytinoğlu A, Altuğlu i. Hepatit $B$ virüs kantitasyonunda iki farklı gerçek zamanlı PCR testinin karşılaştırılması: COBAS AmpliPrep/COBAS TaqMan ve ARTHUS QS-RGQ KiT. Ege Tip Dergisi 2012;51:233.

19. Kaya O, Akçam FZ, Sönmez $Y$, et al. Fibrozisi göstermede non-invaziv yöntemlerin değerlendirilmesi. Viral Hepatit Dergisi 2009;14:91-7.
20. Nwokediuko SC, Ibegbulam O. Quantitative platelet abnormalities in patients with hepatitis B virus-related liver disease. Gastroenterology Res 2009;2:344-9.

21. Henning BF, Zidek W, Linder B, Tepel M. Mean platelet volüme and coronary heart disease in hemodialysis patients. Kidney Blood Press Res 2002;25:103-8.

22. Beyazit $Y$, Sayilir A, Torun $S$, et al. Mean platelet volume as an indicator of disease severity in patients with acute pancreatitis. Clin Res Hepatol Gastroenterol 2012;36:162-8.

23. Şahin F, Yazar E, Yıldız P. Prominent features of platelet count, platelet crit, mean platelet volüme and platelet distribution width in pulmonary tuberculosis. Multidiscip Respir Med 2012;7(38):2-7.

24. Öztürk ZA, Sayıner H, Kuyumcu ME, et al. Mean platelet volume in assessment of brucellosis disease. Biomed Res India 2012:23:5416.

25. Ekiz F, Yüksel O, Koçak E, et al. Mean platelet volume as a fibrosis marker in patients with chronic hepatitis B. J Clin Lab Anal 2011;25:162-5.

26. Turhan O, Coban E, Inan D, Yalcin AN. Increased mean platelet volume in chronic hepatitis B patients with inactive disease. Med Sci Monit 2010;16:202-5.

27. Purnak T, Olmez $S$, Torun $S$, et al. Mean platelet volume is increased in chronic hepatitis $C$ patients with advancedf ibrosis. Clin Res Hepatol Gastroenterol 2013;37:41-6.

28. Karaman H, Karakükcü $C$, Karaman $A$, et al. Mean platelet volume as a fibrosis marker in patients with chronic hepatitis C. Turk J Med Sci 2013;43:39-45.

29. Ceylan B, Fincanci M, Yardimci C, et al. Can mean platelet volume determine the severity of liver fibrosis or inflammation in patients with chronic hepatitis B? Eur J Gastroenterol Hepatol 2013;25:60612

30. Ceylan B, Mete B, Fincanci $M$, et al. New model using platelet indices to predict liver fibrosis in patients with chronic hepatitis $B$ infection. Wien Klin Wochenschr 2013;125:453-60.

31. Yilmaz B, Aydin H, Can G, et al. The relationship between fibrosis level and blood neutrophil to lymphocyte ratio in inactive hepatitis B carriers. Eur J Gastroenterol Hepatol 2014;26:1325-28

32. Yeşil A, Coşgun S, Erdem Eet al. The relationship between fibrosis level and blood neutrophil to lymphocyte ratio in chronic HBV patients. Akademik Gastroenteroloji Dergisi 2013;12:66-8.

33. Uluca U, Sen V, Güneş $A$, et al. Evaluation of neutrophil to lymphocyte ratio and mean platelet volume in inactive hepatitis $B$ carriers. Mustafa Kemal Üniversitesi Tıp Dergisi 2015;6:8-13.

34. Chen L, Lou $Y$, Chen $Y$, Yang J. Prognostic value of the neutrophil-to-lymphocyte ratio in patients with acute-on- chronic liver failure. Int J Clin Prac 2014:68:1034-40. 